\title{
SNAKE-BITE IN NEPAL
}

\author{
Chaudhary $\mathrm{S}^{1}$, Singh $\mathrm{S}^{2}$, Chaudhary $\mathrm{N}^{3}$, Mahato $\mathrm{SK}^{3}$
}

\begin{abstract}
Snake-bite is one of the diseases which is included in the World Health Organization's (WHO) list of neglected tropical diseases. It is a well-known life threatening medical emergency commonly seen in farmers, plantation workers, herders, fishermen, snake restaurant workers and other food producers. In Nepal, snake-bite take a heavy toll of human lives. It is due to poor health services in rural areas especially for antisnake venom (ASV) treatment facility. Exact magnitudes of problem and mortality from snake-bite are very difficult to estimate due to serious misreporting. This review article aims to discuss the epidemiology, clinical features, diagnosis, treatment and prevention of snake-bite envenomation in South Asia region particularly in Nepal and helping in improving the knowledge and understanding of snake-bite to save precious human lives.
\end{abstract}

KEYWORDS: Antivenin, Antisnake venom, Mortality, Neurotoxicity, Snake-bite

1. Associate Professor, Department of Internal Medicine, Universal College of Medical Sciences \& Teaching Hospital, Bhairahawa, Nepal

2. Intern, Universal College of Medical Sciences \& Teaching Hospital, Bhairahawa, Nepal

3. Assistant Professor, Department of Pediatrics, Universal College of Medical Sciences \& Teaching Hospital, Bhairahawa, Nepal

\author{
For Correspondence \\ Dr. Shatdal Chaudhary \\ Associate Professor, \\ Department of Internal Medicine, \\ Universal College of Medical Sciences \& Teaching \\ Hospital, Bhairahawa, Nepal \\ E-mail: shatdalchaudhary@yahoo.com
}




\section{INTRODUCTION}

Snake is a beautiful creature. Cobras are considered sacred and even traditionally worshiped by Hindus and Buddhists and have a special place in ancient mythology. Snake-bite is a well-known, life threatening medical emergency commonly seen in rural areas of developing tropical and subtropical countries where the large number of cases of envenomation and often deaths are reported. In 2009, it was included in the WHO's list of neglected tropical diseases. Nepal is an agriculture based country which has a vast agriculturally fertile terai (Plain) region with hot climate and high seasonal rainfall. It also has high density of rodents, reptiles and amphibian flora which makes it an ideal habitat for snake to live and hibernate. Snake-bite is an important occupational injury affecting farmers, plantation workers, herders, fishermen, snake restaurant workers and other food producers. Open-style habitation and the practice of sleeping on the floor also expose people to bite from nocturnal snakes. It results in the death or chronic disability to many persons of active younger age group. Snake-bite has a high fatality due to various factors. There is lack of public awareness, education, widespread myths and superstition regarding snake-bite which restricts patients in seeking proper treatment in antisnake venom treatment centres. Large number of patients first go to the traditional healers which lead to important significant delays in getting timely treatment. There are a number of victims who die even after reaching the hospital because of inadequate treatment due to poor health infrastructure, wide species variation, limited availability of antisnake venom, and inexperience in handling such cases, unavailability of ventilators and poor compliance with treatment protocols.

\section{METHODOLOGY}

Articles were searched in Medline through PubMed using various terms including "snake," "snake-bite," "envenoming, " "venom" and "antivenin". Various articles from South Asian countries especially from Nepal were retrieved. Further additional articles were obtained by citation tracking of review and original articles. Various guidelines published by WHO and South Asian countries were also included in writing this review.

\section{EPIDEMIOLOGY}

The two regions where snake-bite is seen frequently are South East Asia and Africa. In Africa the incidence of snake-bite varies from $300-500$ bites per 100,000 populations in forested regions to 50-100 bites per 100,000 in dry savannah and the
Sahara. ${ }^{1}$ India has the highest number of deaths due to snakebites in the world where 35-50 thousand people die per year., ${ }^{2,3}$ In Pakistan, 40 thousand cases of snake-bites are reported annually, among them 8,200 were fatal. ${ }^{2,4}$ Around 33 thousand envenomed snake-bite victims are reported annually from government hospitals of Sri Lanka. ${ }^{2}$ Incidence of bites by venomous snakes in the United States is approximately 7000 to 8000 per year, of which 5 or 6 result in death. ${ }^{5}$ Exact magnitude of problem and mortality from snake-bite is very difficult to estimate due to lack of proper data in Nepal. Existing epidemiological data remains fragmented and the true impact of snake-bite is very likely to be underestimated. Large numbers of snake-bite victims are still being treated by traditional healers. Hospital records are the only source of information for most snake-bite reported in Nepal. The majority of the rural population do not go to a doctor following snake-bite. This may be attributed to lack of awareness of the efficacy of medical treatment with antivenins, lack of availability of snake antivenins in the public hospitals, lack of transport facilities and inability to afford transportation. ${ }^{6}$ It has been estimated that more than 20 thousand cases of snake-bite with a thousand deaths occur every year in Nepal. ${ }^{7}$ In a survey conducted between 1980 and 1985 by the Ministry of Health 3189 cases of snakebite with 144 deaths were recorded from 15 district hospitals. Overall death rate among all the cases of snake bite was $4.5 \%{ }^{8}$ In a community-based survey conducted in Southeast Nepal in 2002, revealed annual incidence and mortality rates of snake-bite 1,162/100,000 and $162 / 100,000$ respectively. ${ }^{9}$ It is a significant medical problem that has important implications for the nutrition and economy of the countries where it occurs commonly.

Bites are more frequently seen in young men, which reflect the outdoor activity of males in the society. It results in high degree of exposure and contact with poisonous snakes. In the study from Eastern Nepal it was found that 75 percent of the patients were in the age group of 11- 40 years. ${ }^{10}$ The incidence of snake-bite is higher during the rainy season, flood and periods of intense agricultural activity and less in the winters. ${ }^{11}$ This can be related to the high seasonal rainfall, abundant natural vegetation and high density of rodents, reptiles and amphibians making it an ideal habitat for snakes to live. During rainy season as there is an increase in human agricultural activities, it leads to increase exposure between man and snake, finally favoring snake bite. On the other hand fewer cases are reported in winters which can be attributed to the hibernation of snakes during the extreme fall in environmental temperature. ${ }^{12}$ Higher incidence of snake-bite in males has been recorded, ${ }^{13}$ though male to female ratios varied..$^{14,15}$ It is likely that the majority of the victims were either farmers or housewives in a primarily agrarian society of 
Nepal. ${ }^{7}$ The majority of bites occurs in lower extremities due to stamping while walking ${ }^{16}$ and in hands while cutting grass in the field. ${ }^{7,}$ Alcohol intoxication of the victim is a important factor in many envenomations. ${ }^{17}$ Bites in the head and neck region may occur during sleep on ground as kraits often enter human dwelling at night in search of food. ${ }^{\text {? }}$

\section{SNAKES IN SOUTHASIAAND NEPAL}

Globally more than 3 thousand species of snakes have been identified of which about $15 \%$ are poisonous. ${ }^{18-21}$ In Nepal, a total of 79 species of snakes have been reported so far, in which 20 are poisonous. The most commonly reported poisonous snakes from terai and inner terai includes, 4 species of kraits, 3 species of cobras, 9 species of vipers, 1 species each of coral snake, Himalayan pit viper, mountain pit viper and Russel's viper. ${ }^{4,19,22-23}$ In India, out of the 216 species of snakes, 60 are considered poisonous. ${ }^{24}$ The distribution of these poisonous snakes depends largely on the geography and climate. The Himalayan pit viper has been found up to an altitude of 5,000 meters whereas the pit vipers inhibit wooded mountain slopes below 3,000 meters. ${ }^{25}$ The species of krait are found below 2,000 meters while the species of cobras are confined to the terai. Most of the time $\left(77 \%,{ }^{13} 60 \%,{ }^{26}\right.$ and $52 \%{ }^{15}$ ) snakes species responsible for bite are unidentified.In a study from Pokhara, green pit-vipers were identified for bite in $23 \%$ cases. ${ }^{14}$ Whereas in a study from Lumbini Zonal Hospital, Butwal, snakes species identified were kraits (29\%),cobras $(10 \%)$ and vipers $(1 \%) .{ }^{26}$ Similarly in another study $40 \%$ were kraits and $8 \%$ were cobras. ${ }^{15}$ Among various venomous species of snakes of Nepal, cobras (Genus: Naja) and kraits (Genus: Bungarus) are the two important genera found in Eastern Nepal. The eastern and western diamondback rattle snakes account for most fatalities in USA. ${ }^{5}$ Herpetologists from zoos or aquariums can be used to assist in species identification. The venom glands in Elapids and Viperids are situated behind the eye and are surrounded by compressor muscles. Venom glands are connected to fangs which are modified teeth. In Elapids, the fangs are short and are mounted on a relatively fixed maxilla in front of the mouth. In Viperids the fangs are long and mounted on a rotatable maxilla, facilitating flat folding against the roof of the mouth. In humans, snakes usually inject venom subcutaneously or intramuscularly. The average dry weight of venom injected at a strike is approximately $60 \mathrm{mg}$ (N. naja), $13 \mathrm{mg}$ (E.carinatus) and $63 \mathrm{mg}$ (D. russelii) respectively.

In Nepal Cobra bites usually occur in the daytime, commonly at dawn and dusk. Kraits rarely bite man in the day time, although this has been known in unusual circumstances, such as when a Krait enters human dwelling at night in search of food. Krait bites usually occur at night on sleeping people and may go unnoticed, so that early morning pain in the abdomen with ptosis and diplopia. The prompt identification of the signs and symptoms of snake-bite and treatment with adequate doses of ASV in systemic envenoming have key role in ensuring the survival of the patient. Morphological and other advanced immuno diagnostic techniques can be useful for rapid diagnosis and identification of species of reptiles.

\section{SNAKE VENOM}

Snake venom is made mostly from proteins but it is a highly complex mixture of protein sranging from 6 to $100 \mathrm{kD},{ }^{27}$ peptides, non protein toxins, carbohydrates, lipids, amines and other molecules. The chemical composition of venom varies with the species. Each venom contains more than a hundred different proteins: enzymes which may constituting 80-90\% of viperid and $25-70 \%$ of elapid venoms. ${ }^{3}$ These include digestive hydrolases, hyaluronidase, and activators or inactivators of physiological processes, such as kininogenase. Most venoms contain l-amino acid oxidase, phosphomonoand diesterases, 5'-nucleotidase, DNAase, NADnucleosidase, phospholipase A2 and peptidases. There are also non-enzymatic polypeptide toxins, and non-toxic proteins such as nerve growth factor. The composition of different snake venoms can vary considerably different between snakes in different geographical locations and based on diet, age, season and environment. The various manifestations of snake bite could be attributed to complexity of venom to some extent. The snake venoms are mainly characterized as neurotoxic and hemotoxic. The neurotoxic venoms act at molecular level, by disrupting the neuromuscular junctions, limiting muscle activity while hemotoxic venoms cause tissue destruction in body systems besides their effect on circulatory system.

Zinc metalloproteinase haemorrhagins: Damage vascular endothelium, causing bleeding. ${ }^{3}$

Procoagulant enzymes: Venoms of Viperidae and some Elapidae and Colubridae contain serine proteases and other procoagulant enzymes that are thrombin-like or activate factor $\mathrm{X}$, prothrombin and other clotting factors. These enzymes stimulate blood clotting with formation of fibrin in the bloodstream. Paradoxically, this process results in incoagulable blood because most of the fibrin clot is broken down immediately by the body's own plasmin fibrinolytic system. Sometimes within 30 minutes of the bite, the levels of clotting factors are so depleted ("consumption coagulopathy") that the blood will not clot. Some venoms contain multiple anti-haemostatic factors. For example, 
Russell's viper venom contains toxins that activate factors $\mathrm{V}$, $\mathrm{X}$, IX and XIII, fibrinolysis, protein $\mathrm{C}$, platelet aggregation, anticoagulation and haemorrhage. ${ }^{3}$

Phospholipase A2 (lecithinase): The most widespread and extensively studied of all venom enzymes. It damages mitochondria, red blood cells, leucocytes, platelets, peripheral nerve endings, skeletal muscle, vascular endothelium, and other membranes, produces presynaptic neurotoxic activity, opiate-like sedative effects, leads to the autopharmacological release of his tamine and anti-coagulation.

Acetylcholinesterase: Although found in most elapid venoms, it doesnot contribute to their neurotoxicity. ${ }^{3}$

Hyaluronidase: Promotes the spread of venom through tissues. Proteolytic enzymes (metalloproteinases, endopeptidases or hydrolases) and polypeptide cytotoxins ("cardiotoxins"): Increase vascular permeability causing oedema, blistering, bruising and necrosis at the site of the bite.

Venom polypeptide toxins ("neurotoxins"): Postsynaptic $(\alpha)$ neurotoxins such as $\alpha$-bungarotoxin and cobrotoxin, consistof 60-62 or 66-74 amino acids. They bind to acetylcholine receptors at themotor endplate. Presynaptic $(\beta)$ neurotoxins such as $\beta$-bungarotoxin, crotoxin,and taipoxin, contain 120-140 amino acids and a phospholipase A subunit.These release acetylcholine at the nerve endings at neuromuscular junctions and then damage the endings, preventing further release of transmitter.

Quantity of venom injected at a bite, "dry bites" is very variable, depending on the species and size of the snake, the mechanical efficiency of the bite, whether one or two fangs penetrated the skin and whether there were repeated strikes. ${ }^{3}$

\section{CLINICAL FEATURES}

Clinical manifestations of snake-bite vary according to the species responsible for the bite and the amount of venom injected in the body. The identity of the biting snake can be confirmed by examining the dead snake or from the clinical features. This will be especially helpful in choosing appropriate antivenom and preventing likely complications. Snake parts should not be handled directly since the bite reflex in recently killed or decapitated snakes remains intact, rendering them capable of inflicting a bite. ${ }^{28}$

\footnotetext{
Victims of snake-bite may suffer any or all of the following:

Local envenoming confined to the part of the body that has been bitten.

2. Systemic envenoming involving organs and tissues away from the part of $t$ he body that has been bitten.

3. Effects of anxiety prompted by the frightening experience of being bitten and by exaggerated beliefsabout the potency and speed of action of snake venoms. These symptoms can be misleading for medicalpersonnel.

4. Effects of first -aid and other pre -hospital treatments that may cause misleading clinical features.
}

Patient can have various symptoms even if they are not bitten by poisonous snake due to fear and anxiety. Many people believe that any bite from a venomous snake will result in envenomation but in fact, 25 percent of all pit-viper bites are "dry" and do not result in envenomation. ${ }^{29}$ There may be wide ranges of misleading problems like palpitation, sweating, tremors and even vasovagal shock. Patients may hyper ventilate and may develop pin and needles sensation in the extremities, stiffness or tetany. There can be various problems which may arise from first aid and traditional treatment. Constricting bands or tourniquets may cause pain and swelling which may mimic local envenomation. Patients may develop gangrene sometimes if they are tightened excessively. Forced emesis may cause aspiration pneumonia, bronchospasm and pneumothorax. If the biting snake is not identified, the syndromic diagnosis should be made based on the emerging pattern of symptoms, signs and laboratory investigations. It may suggest the likely biting species and helps in starting appropriate treatment.

There may be increasing local pain which may be burning, bursting or throbbing at the site of the bite. Patient may gradually develop local swelling that may extend proximally. There may be tender lymphadenopathy which is usually in inguinal or femoral areas, following bites in the lower limb or in epitrochlear or axillary areas following bites in the upper limb. Local symptoms are more prominent in Viper bites whereas Kraits, sea snakes and Philippine cobra bites may be virtually painless with minimal local swelling. Patients can have general nonspecific symptoms like nausea, vomiting, malaise, abdominal pain, weakness, drowsiness and prostration. Specific features like visual disturbances, dizziness, faintness, collapse, shock, hypotension, arrhythmias, pulmonary edema and conjunctival chemosis are suggestive of cardiovascular involvements which are specially seen in Viperidae bite. Manifestations similar to bleeding and clotting disorders are also seen in Viperidae bite. These patients can come with bleeding from gingival sulci, recent wounds like venipuncture site and snake-bite site or from old partly healed surgical/nonsurgical wounds. Patients can also develop spontaneous bleeding from gums, nose, conjunctiva, gastrointestinal tract, urinary bladder, lungs, retina, uterus and vagina. Intracranial hemorrhage must be suspected in patients who have lateralizing neurological signs or coma. Acute and chronic pituitary or adrenal insufficiency can be caused by Viper bite. Neurological symptoms are seen in Elapidae and Russell's viper bite. These patients may have drowsiness, paraesthesia, loss of taste and smell, ptosis, diplopia due to external ophthalmoplegia, facial paralysis, inability to open the mouth, inability to protrude the tongue from the mouth, nasal speech, nasal regurgitation, frothing of 
saliva dysphagia and paralysis of the muscles of the hands and feet. If patient remains untreated, respiratory and general flaccid paralysis may develop. Rhabdomyolysis is seen in patients bitten by sea snakes, some krait species like Bungarus niger, B. candidus and, western Russell's viper- Daboia russelii. These patients will have generalized pain, stiffness and tenderness of muscles, trismus and myoglobinuria. The patients may die of hyperkalaemia, cardiac arrest, acute kidney injury. Renal involvement is seen Viperidae and sea snakes. They may present with loin pain, haematuria, haemoglobinuria, myoglobinuria, oliguria and features of uremia. Some patient can develop long term complications after snake-bite like chronic ulceration, contractures, arthritis, osteomyelitis, limb amputation and malignant transformation of skin ulcers. A number of methods including ELISA have been developed for detection of venom and antibodies. Species specific ELISA aids in diagnosis and subsequent management by identifying the exact species of snake, monitoring the circulating venom antigen. In peripheral centers 20-Minute Whole Blood Clotting Test may be helpful in the diagnosis and management of viper bite.

\section{TREATMENT}

Reassure the victim who may be very anxious and immobilize the patient in a comfortable position. Affected limb should be kept below the level of the heart. Any movement of the body increases absorption of venom into the bloodstream and lymphatic. First-aid treatment is carried out immediately by the patients himself after the bite before reaching the hospital with the aim to retard systemic absorption of venom, control distress, preserve life and prevent complications. Consider pressure-immobilization or pressure pad where facilities are available. But most of the traditional first-aid methods like making local incisions, ${ }^{30}$ sucking the venom out of the wound, tourniquets around the limb, ${ }^{31}$ application of chemicals, herbs or ice pack have been proved to be useless or sometimes even dangerous. Tight tourniquets proximal to bite are not recommended as this method can be extremely painful and dangerous. If the tourniquet was left for 40 minutes, the limb may develop is chemia or gangrene. Any interference with the bite wound like incisions, rubbing, vigorous cleaning, massage, application of herbs or chemicals are strongly discouraged as this may introduce infection, increase absorption of the venom and increase local bleeding. A suitable safe transport must be made available to shift the patient to a proper treatment centre where they can receive appropriate medical care.

Immediate transportation of the victim to the nearest health centre where anti-snake venom serum is available is the most important first aid measure. During transfer support the airway and breathing, administer oxygen and establish an intravenous line in the unaffected limb. A stretcher, bicycle, motorbike, cart, horse, motor vehicle, train or boat can be used. Transport by motorcycle or other motor vehicles has been found effective especially in rural areas and is the key to save time. Lack of transport facilities and inability to afford transportation leads to delay or inability in seeking medical treatment in a large number of the victims which may lead to respiratory failure and death. With the passage of time venom gets bound to the tissues and thus cannot be neutralized by anti-snake venom. Visit to traditional healers and unawareness of the effective medical management of snake-bite may be other reasons for delayed arrival to the hospital. If the victim has no signs of envenomation, admit the patient and observe for 24 hours. If the biting species is unknown, the patient should be observed closely to allow recognition of the emerging pattern of symptoms, signs and results of laboratory tests. The clinical syndromic diagnosis should be made and the victim should be treated empirically according to the suspected species. Once patient reaches the hospital airway patency, respiratory movements, arterial pulse and level of consciousness must be checked immediately and dealt appropriately. During initial evaluation, base-line circumferential measurements at several points above and below the site of the bite should be documented. Measurements should be repeated and documented every 15 to 20 minutes until local progression of swelling subsides. If possible monitoring in an intensive care unit is recommended for all patients treated with antivenom. Base-line laboratory studies should include a complete blood count with platelet count, coagulation profile, measurement of fibrin degradation products, electrolytes, blood urea nitrogen, and serum creatinine, and urinalysis. Laboratory studies should be repeated after each infusion of antivenom. Other tests like creatine kinase, blood typing with cross-matching, chest radiography, and electrocardiography can be done, if required. ${ }^{32}$

Patients with neurotoxic envenoming may present with terminal respiratory failure due to paralysis of the respiratory muscles and may require endotracheal intubation and ventilatory support. Some patients may present with hypotension and shock. It may be a result of anaphylaxis induced by the venom, direct cardiovascular effects of the venom, hypovolaemiaand release of inflammatory vasoactive mediators or due to profuse bleeding. Patients with sea snake, certain kraits and Russell's vipers bite can come in cardiac arrest and hyperkalaemia due to rhabdomyolysis. They may require immediate resuscitation. Some patients may present late with acute kidney injury, septicemia and local necrosis which should be managed appropriately. 
The only specific antidotes to snake venoms are immunoglobulin antivenoms which are now recognized as essential drugs. Antivenom treatment for snake-bite was first introduced by Albert Calmette at the Institut Pasteur in Saigon in the 1890s. Antivenom is usually whole $\mathrm{IgG}$ or pepsin refined $\mathrm{F}(\mathrm{ab})$ fragments of $\mathrm{IgG}$ which is derived from the plasma of a horse, mule or donkey (equine) or sheep (ovine) that has been immunized with the venoms of one or more species of snake. Monovalent antivenom neutralizes the venom of only one species of snake. Polyvalent antivenom neutralizes the venoms of several different species of snakes, usually the most important species, from a medical point of view, in a particular geographical area.

\section{Figure 1:Antisnake venom available in local market.}

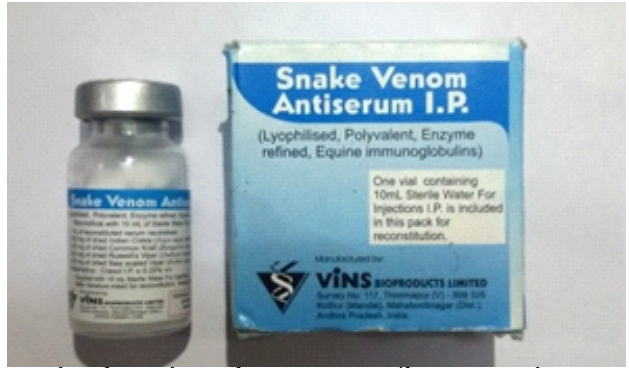

Antibodies raised against the venom of one species may have cross-neutralizing activity against other venoms, usually from closely related species. This is known as para specific activity. Usually lyophilized antivenoms have shelf life of about 5 years and should be stored at below $25^{\circ} \mathrm{C}$ whereas liquid antivenoms have shelf life of about 2-3 years and should be stored at $2-8^{\circ} \mathrm{C}$ and not frozen. In Nepal ASV is imported from India. The Indian antivenom manufacturers' "polyvalent antisnake venom serum" is raised in horses using the venoms of the four most important venomous snakes in India (Indian cobra, Najanaja; Indian krait, Bungarus caeruleus; Russell's viper, Daboia russelii; saw-scaled viper, Echis carinatus), although the validity of the concept of "the big four" is increasingly challenged by the discovery that other species are also important in certain regions e.g. H. hypnale in SouthWest India; Trimeresurus malabaricus in southern India; Echiscarinatusso chureki in Rajasthan. There are seven pharmaceutical laboratories in India that produce ASV against four medically important Indian snake species. ${ }^{33}$

ASV treatment is advised in patients who are known to be bitten by poisonous snake or suspected snake-bite patients who develops features of local and systemic envenomation. If it is indicated, it should be started as soon as possible. Treatment of a snake-bite envenoming costs lifetime savings to the victim due to high cost of the ASV, therefore since 1999 the Nepal government has made it free to the Nepalese poisonous snake-bite victims. Skin and conjunctival hypersensitivity tests with antivenom are not advised these days as it only reveals IgE mediated Type I hypersensitivity to horse or sheep proteins and do not predict majority of early or late antivenom reactions. It may cause delay in treatment and can in themselves be sensitizing. There is no absolute contraindication to antivenom treatment, but in patients who have history of reaction to horse or sheep serum should be careful. These high risk patients may be pre-medicated empirically with subcutaneous adrenaline, intravenous Antihistamines, H2 receptor blockers like ranitidine and corticosteroid. All patients should be watched carefully for two hours after the completion of antivenom administration and should be treated with epinephrine/adrenaline at the first sign of a reaction.

If the biting species is known, monovalent antivenom should be used, as this may be less expensive and may require in a lower dose in comparison to polyvalent antivenom. Polyvalent antivenoms are preferred in many developing countries because it is difficult in identifying the species responsible for bites in most of the times. Lyophilized antivenoms are reconstituted, usually with $10 \mathrm{ml}$ of sterile water for injection per ampoule. Reconstituted freeze-dried antivenom can be given by slow intravenous injection at the rate of not more than $2 \mathrm{ml} /$ minute or diluted in approximately 5-10 $\mathrm{ml}$ of isotonic fluid per $\mathrm{kg}$ body weight and is infused at a constant rate over a period of about one hour. Local administration of antivenom at the site of the bite is not recommended as it has not been found to be effective, can be extremely painful and may increase intra compartmental pressure. Intramuscular administration of antivenom is not advised except in situation where intravenous access is not possible. The recommended dose is often varies from manufacturer to manufacturer and it is usually based on the amount of antivenom required to neutralize the average venom yield when captive snakes are milked of their venom. In practice, the choice of an initial dose of antivenom is usually empirical.

In view of multiple treatment modalities followed by treating physicians in the country, National guideline for the management of snake-bite was introduced by Epidemiology and Disease Control Division (EDCD), Government of Nepal in 2003. Two vials of polyvalent antisnake venom serum are given as bolus followed by intravenous infusion of 4 vials 4 to 6 hourly to the patients with signs of envenomation. ${ }^{34}$ Similarly the Ministry of Health \& Family Welfare, Government of India has drafted the National Snake Bite Management Protocol to provide guidelines for proper management of 
snake-bites ${ }^{35,36}$ It recommends initial dose of 10 vials $(100 \mathrm{ml})$ of polyvalent ASV for adults and children over one hour. The concept of aggressive use of antisnake venom within 3 hours of the development of first sign of envenomation, ptosis, is based on research that the use of ASV after the development of respiratory paralysis is not beneficial and Russells Viper injects on average $63 \mathrm{mg}$ of venom. Children are given exactly the same dose of antivenom as adults because snakes inject the same dose of venom into children and adults. Adequacy of antivenom dose is assessed with favorable responses in terms of clinical features and laboratory investigations. In general, the patient feels better, spontaneous systemic bleeding stops within 15-30 minutes, blood coagulability restores in 3-9 hours, blood pressure improves, neurotoxic features begin to improve in 30 minutes after antivenom (may take several hours), active haemolysis and rhabdomyolysiscease within a few hours and urine returns to its normal color. In patients who continue to bleed briskly, the dose of ASV should be repeated within 1-2 hours. If the blood remains incoagulable six hours after the initial dose of antivenom, the same dose should be repeated. Hypovolemia should be corrected with colloids or crystalloids and controlled by observation of the central venous pressure. Ancillary vasopressor drugs may be used when required. In case of deteriorating neurotoxicity or cardiovascular signs, the initial dose of ASV should be repeated after 1-2 hours, and full supportive treatment must be considered. There supportive measures can be used as when required. Intubation and mechanical ventilation can be used in patients with respiratory paralysis. Fresh frozen plasma (FFP) and cryoprecipitate with platelet concentrates or, if these are not available, fresh whole blood can be used in patients with coagulation abnormality. Patient with acute kidney injury should be treated accordingly and dialysis can be done, if indicated. Patients with severe local envenoming and necrosis, prophylactic broad spectrum antibiotics should be started and proper care of wound with appropriate surgical debridement should be done.

After getting antivenom, approximately $10 \%$ of patients can develop anaphylactic reactions but may range from 23 percent to 56 percent. ${ }^{37-39}$ These reactions can be divided in to either early, pyogenic or late depending on time of onset. An early anaphylactic reaction usually occurs within few minutes to hours of starting antivenom. Here patients start to itch mostly over the scalp, develop urticarial rashes with fever, tachycardia, nausea, vomiting, abdominal pain, diarrhoea and dry cough. Few of these patients may develop severe lifethreatening anaphylaxis and develop shock, bronchospasm and angioedema leading to death. Pyrogenic reactions are caused by pyrogen contamination during the manufacturing process. It usually develop within 1-2 hours after treatment and patients may start having fever, chills, rigors, convulsions and shock.

Late reactions develop 1-12 days after treatment. Here patients present with fever, nausea, vomiting, diarrhoea, itching, recurrent urticaria, joint swelling, muscle pain, enlarged lymph node, joint swellings, mononeuritis multiplex, encephalopathy, and immune complex nephritis. Epinephrine (adrenaline) in an initial dose of $0.5 \mathrm{mg}$ for adults and $0.01 \mathrm{mg} / \mathrm{kg}$ body weight for children is given intramuscularly as soon as possible if the features of anaphylactic reactions develop. After that an intravenous antihistamine anti-H1 blocker such as chlorpheniramine maleate and intravenous hydrocortisone are given. For pyrogenic reactions cold sponging is done and antipyretic like paracetamol is given. Late Serum sickness is a type III hypersensitivity reaction that may occur 7 to 21 days after the completion of treatment. It is manifested as fever, rash, arthralgias, and lymphadenopathy and are treated with five days course of oral antihistamine. Patients who fail to respond in 24-48 hours should be given a 5-day course of oral prednisolone.

\section{PREVENTION}

Public awareness and education must be raised regarding snake bites. The most important way for prevention of snake bite is to avoid snakes as far as possible. It is advised not to handle, threaten or attack a snake, neither trap a snake. Keep children away from snake-infested areas. Be especially careful about snake-bites after rains, during flooding, at harvest time and at night. Never keep livestock, birds especially chickens in the house as snakes may be attracting to them. Food and food products must be stored in rat-proof containers. Do not sleep on the ground and if you have to sleep on the ground use a mosquito net that is well covered under the mattress. Destroy all the possible hiding places for snakes like termite mounds, heaps of rubbish, building materials etc. Tree branches should not be touching the house. Grass and bushes in and around the house must be kept short. Use light while walking outside the house or while going to toilets at night. Never walk bare-footed or wearing sandals, when walking in the dark or in undergrowth Instead of it is advised to use proper shoes or boots and long trousers. Do not put your hands into holes or nests or any hidden places where snakes might rest. Be careful when handling dead or apparently dead snakes even an accidental scratch from the fang of a snake's severed head may inject venom. While working in rivers and the sea one should avoid touching sea snakes caught in nets and on lines. 


\section{CONCLUSION}

Snake-bite is still a major problem in developing countries like Nepal, causing significant morbidity and mortality. There is gross disparity in the management and outcome of snakebite in different hospitals. There is a great need to improve in existing health care conditions for effective management of snake-bite.It requires training of the personnel engaged in the emergency health care management, development of national guidelines based on the clinical trials, improving the distribution and easy availability of antivenom. Efforts are needed to develop studies on the epidemiology of snake-bite and education of the population at risk. Development and manufacturing of antisnake venom for local snakes is highly recommended.

\section{REFERENCES}

1. WHO. Blood Products and Related Biologicals:Animal sera Available from website.

http://www.who.int/blood products/animal_sera/en(accessed 2005).

2. Kasturiratne A, Wickremasinghe AR, de Silva N, Gunawardena NK, Pathmeswaran A, et al. The global burden of snakebite: a literature analysis and modelling based on regional estimates of envenoming and deaths. PLoSMed 2008; 5: e218. http://dx. doi. org /10.1371/journal.pmed.0050218PMid:18986210 PMCid: PMC2577696

3. Warrell DA. Epidemiology of snake-bite in South-East Asia Region. In: Warrell DA (ed.) Guidelines for the management of snakebite. New Delhi: WHO regional office for Southeast Asia. 2010;1-135.

4. Chippaux JP. Snake-bites: appraisal of the global situation. Bull World Health Organ. 1998; 76: 515524.PMid:9868843 PMCid: PMC2305789

5. Langley RL, Morrow WE. Deaths resulting from animal attacks in the United States. Wilderness Environ Med. 1997;8:8-16. http://dx.doi.org/10.1580/1080-6032(1997) 008[0008:DRFAAI] 2.3.CO;2

6. Rahman R, Faiz MA, Selim S, Rahman B, Basher A, et al. Annual Incidence of Snake Bite in Rural Bangladesh. PLoSNegl Trop Dis. 2010; 4(10): e860.http://dx.doi.org/10.1371/journal. pntd. 0000860PMid:21049056 PMCid:PMC2964284

7. Devkota UN, Steinmann JP, Shah LN. Snakebite in Nepal; A study from Siraha District, Nepal. J. Nep. Med. Ass. 2000; 39(134) :203209.
8. World Health Organisation. Zoonotic disease control: Baseline epidemiological study on snakebite treatment and management. Nepal WHO weekly Epidemiolog Rev 1987; 62: 319- 20.

9. Sharma SK, Chappuis F, Jha N, Bovier PA, Loutan L, Koirala S. Impact of snake bites and determinants of fatal outcomes in south eastern Nepal. Am J Trop Med Hyg2004. 71:22348.

10. Sharma SK, Koirala S, Dahal G, Sah C. Clinico-epidemiological features of snakebite: a study from Eastern Nepal. Trop Doct. 2004:34(1): 20-2.PMid:14959965

11. Suleman MM, Shahab S, Rab MA. Snake bite in the Thar Desert. J PakMed Assoc. 1998; 48: 306308.PMid:10087752

12. Joshi HS, Mahmood SE, Joshi MC, Shaifali I and Srivastava PC.Clinico-Epidemiological Profile of Snake Bite Cases in Western Nepal. TAF Prev Med Bull 2012; 11(1): 57-62. http://dx.doi.org/10.5455/pmb.20111023012020

13. Koirala DP, Gauchan E, Basnet S, Adhikari S, BK G. Clinical Features, Management and outcome of Snake Bite in Children in Manipal Teaching Hospital. Nepal Journal of Medical sciences 2013;2(2) :119-24.http://dx.doi.org/10.3126/njms.v2i2.8954

14. Pandey DP. Epidemiology of Snake Bites Based on Hospital Survey in Chitwan and Nawalparasi Districts, Nepal. Journal of Nepal Health Research Council. 2006; 4(2): 51-7.

15. Paudel KM, Sharma S. Study of Clinico-Epidemiological Profile and Outcome of Poisonous Snake Bites in Children. J. Nepal Paediatr. Soc. 2012; 32(1):47-52.http://dx.doi.org/10.3126/jnps .v32i1.5948

16. Alirol E, Sharma SK, Bawaskar HS, Kuch U, Chappuis F. Snake Bite in South Asia: A Review. PLoSNegl Trop Dis. 2010; 4(1): e603.http://dx.doi.org/10.1371/journal.pntd.0000603PMid:201 26271 PMCid:PMC2811174

17. Wingert WA, Chan L. Rattlesnake bites in southern California and rationale for recommended treatment. West J Med 1988; 148:37-44.PMid:3277335 PMCid:PMC1026007

18. Gold BS, Dart RC, Barish RA. Bites of Venomous Snakes. NEngl $J$ Med2002;347:34756.

http://dx.doi.org/10.1056/NEJMra 013477 PMid:12151473

19. Warrell DA, O'Shea M. Snakes and snakebite in Nepal. Tropical Doctor. 199; Vol. 28; 223-226.

20. Vonk FJ, Jackson K, Doley R, Madaras F, Mirtschin PJ, Vidal N. Snake venom: From fieldwork to the clinic: Recent insights into snake biology, together with new technology allowing high through put screening of venom, bring new hope for drug discovery. Bioessays 2011;33:269-279. http://dx.doi.org/10.1002/bies.201000117PMid:21271609 
21. Russell FE. When a snake strikes. Emerg Med 1990;22 (12):205,33-4, 37-40, 43.

22. Hansdak SG, Lallar KS, Pokharel P, Shyangwa P, Karki P, Koirala S. A clinico-epidemiological study of snake bite in Nepal. Trop Doct. 1998 Oct;28:223-6.PMid:9803844

23. Shah KB. Checklist of the herpetofauna of Nepal with English and Vernacular names. NAHSON Bulletin 1998; 8: 25 - 30

24. Narvencar K. Correlation between timing of ASV administration and complications in snake bites. J Assoc Physicians India. 2006 Sep;54:717-9.PMid:17212020

25. Sharma SK, Pandey DP, Shah KB, Tillack F, Chappuis F, Thapa $C L$ et al. Venomous Snakes of Nepal a photographic guide. First edition, B.P. Koirala Institute of Health Sciences, Dharan, Nepal. 2013:1-75

26. Shrestha BM. Outcomes of Snakebite Envenomation in Children. JNepal Paediatr Soc.2011;31:192-7. http://dx.doi.org/10.3126 /jnps.v31i3.5358

27. Stocker KF. Composition of snake venoms. In: Stocker KW, ed. Medical use of snake venom proteins. Boca Raton, Fla.:CRC Press, 1990:33-56.

28. Gold BS, Barish RA. Venomous snakebites: current concepts in diagnosis, treatment, and management. Emerg Med Clin North Am 1992;10:249-67.PMid:1559468

29. Kitchens CS, Van Mierop LHS. Envenomation by the eastern coral snake (Micrurusfulviusfulvius): a study of 39 victims. JAMA1987;258:16158.

http://dx.doi.org/10.1001/jama.258.12.1615

http://dx.doi.org/10.1001/jama.1987.03400120065026

30. Hall EL. Role of surgical intervention in the management of crot aline snake envenomation. Ann Emerg Med 2001;37:17580. http://dx.doi.org/10.1067/mem.2001.113373PMid:11174236
31. Meier J, White J, eds. Handbook of clinical toxicology of animal venoms and poisons. Boca Raton, Fla.: CRC Press, 1995:477.

32. Dart RC, Gustafson RA. Failure of electric shock treatment for rattlesnake envenomation. Ann Emerg Med 1991;20:659-61. http://dx.doi.org/10.1016/S0196-0644(05)82389-3

33. Whitaker $R$, Whitaker $S$. Venom, antivenom production and the medically important snakes of India. CurrSc 2012;103: 635-43.

34. Shah KB, Shrestha JM, and Thapa CL. Department of Health Services Epidemiology and Disease Control Division, Zoonoses Control Sub-Section. Snakebite Management Guideline. 2003: $1-53$.

35. National snakebite management protocol, India. 2008

36. Simpson ID. The pediatric management of snakebite: the national protocol. Indian Pediatr 2007;44:173-6. PMid: 17413192

37. Grace TG, Omer GE. The management of upper extremity pit viper wounds. JHand Surg [Am] 1980;5:168-77. http://dx.doi. org/10. 1016/S0363-5023(80)80149-3

38. White RR IV, Weber RA. Poisonous snakebite in central Texas: possible indicators for antivenin treatment. Ann Surg 1991; 213:466-71.

http://dx.doi.org/10.1097/00000658-199105000-00012

39. Jurkovich GJ, Luterman A, McCullar K, Ramenofsky ML, Curreri PW. Complications of Crotalidae antivenin therapy. $J$ Trauma 1988;28:1032-7. http://dx.doi.org/10.1097/00005373-198807000-00020 PMid: 2899649 